\title{
Feeding behaviour in Littorina littorea: the red seaweed Osmundea ramosissima may not prevent trematode infection
}

\author{
Matilda Olsson, Lillemor Svärdh, Gunilla B. Toth* \\ Department of Marine Ecology, Göteborg University, Tjärnö Marine Biological Laboratory, 45296 Strömstad, Sweden
}

\begin{abstract}
Terrestrial herbivores can use anthelmintic properties of plant secondary metabolites to decrease parasite/parasitoid infections. Secondary metabolites with potential anthelmintic properties have also been described from different seaweed species, but the effects of diet on parasitism in marine herbivores has not been studied previously. In the present study, a combination of laboratory and field experiments was used to test the hypotheses that infection by digenean trematode parasites affects the feeding pattern of herbivorous gastropods (Littorina littorea), and that the seaweed diet prevents parasitism in the snails. Heavily infected snails consumed less of the red seaweed Osmundea ramosissima than uninfected snails, but there was no difference in consumption when snails were offered the green seaweed Ulva lactuca. Healthy snails placed in cages with different food treatments and transplanted to different field sites became infected by trematodes, but there was no significant difference in parasite resistance between snails offered different foods. Furthermore, there was no significant negative relationship between infection abundance and consumption when $O$. ramosissima was incorporated into agar-based artificial diets, indicating that the difference in feeding pattern found in the initial consumption experiment was due to the morphology, and not the chemistry of the seaweeds. In conclusion, these preliminary results do not indicate that parasitized L. littorea feeds on O. ramosissima to prevent parasite infection. However, the hypothesis that algal chemical compounds prevent or decrease parasite infections in herbivores should be tested using additional candidate species before drawing general conclusions about the effect of diet on parasitism in marine systems.
\end{abstract}

KEY WORDS: Anthelmintic $\cdot$ Herbivore $\cdot$ Parasite $\cdot$ Seaweeds $\cdot$ Trematode

\section{INTRODUCTION}

Almost all living organisms serve as a hosts for one or more parasite species, and parasites can have large impacts on the survival, behaviour, reproduction, and population dynamics of their hosts (Scott 1988, Hudson et al. 1998, Mouritsen \& Poulin 2002). The transmission and infection success of parasites, and consequently the patterns of parasite infection, are probably highly dependent on both parasite and host behaviours. It is to the parasite's advantage to behave, or manipulate the host to behave, in a way that increases transmission and infection success of different parasite stages
(Esch et al. 2001). On the other hand, if the host's fitness is decreased by parasite infection, which has been shown in a number of studies (e.g. Huxham et al. 1993, Hudson et al. 1998, Curtis 2002, Desclaux et al. 2004), there should be selection for the host to display behaviours that decrease the probability of becoming infected. Insects can resist infection through ingestion of certain nutritionally inferior plant species, which contain secondary metabolites that have negative effects on the parasitoids (Karban \& English-Loeb 1997, Singer \& Stireman 2003, Singer et al. 2004). Furthermore, previous studies have revealed that chimpanzees ingest plants with anti-parasitic properties 
and that such behaviour aids in the control of intestinal parasites (Huffman 2003). However, no previous studies have, to our knowledge, investigated whether marine herbivores can use their algal diet to prevent or decrease parasitism.

In marine habitats, digeneic trematode parasites are very common and affect a wide range of hosts belonging to different trophic levels and/or functional groups (Rohde 2005). The adult worm develops in predatory seabirds, and after reproduction the eggs are deposited in the birds' faeces. Depending on species, the eggs either hatch and release free-swimming miracidia that penetrate the first intermediate gastropod host, or are ingested and hatch directly inside the gastropods. The miracidia transform into asexually reproducing sporocysts/rediae, which produce freeswimming cercariae that are released from the first intermediate host. The cercariae infect and encyst the second intermediate hosts, which may be herbivorous crustaceans or gastropods, filter-feeding molluscs, or predatory fish. Transmission to the definitive host is always by ingestion of the second intermediate host (Sukhdeo \& Sukhdeo 2004). Marine gastropods of the genus Littorina can act as both first and second intermediate hosts for a number of digenean trematode species in the littoral zone. The snails are abundant on boulder and rocky reef shores, as well as on shallow soft bottoms, and densities can reach several hundred $\mathrm{m}^{-2}$ (authors' pers. obs.). More than 10 species of digeneans infect species of Littorina in the North Atlantic, and trematode prevalence (percent of infected snails in a population) can be locally high (Granovitch \& Johannesson 2000). Observations of parasite prevalence and abundance (parasites per host) are common in marine intertidal habitats (e.g. Galaktionov \& Bustnes 1999, Granovitch \& Johannesson 2000, Svärdh \& Johannesson 2001, Curtis 2002, Granovitch \& Mikhailova 2004, Skirnisson et al. 2004). However, manipulative experimental studies on the processes causing these patterns are still rare (but see Curtis 2002).

A significant number of secondary metabolites with potential importance for drug discovery have been described from different species of algae (Smit 2004). One of the most studied algal groups with antiparasitic properties is the red seaweed family Rhodomelaceae (Sato et al. 1996, Higa \& Kuniyoshi 2000). Among these, the best-known medicinal seaweed is perhaps Digenea simplex, which has been utilized as a folk remedy for the treatment of roundworm disease in Asia over centuries. An active substance in the alga, $\alpha$-kainic acid, has been isolated and developed into an anthelmintic drug (Higa \& Kuniyoshi 2000). Another anthelmintic folk medicine used in Japan is the red alga Chondria armata, belonging to the same family as $D$. simplex. The anthelmintic substance of $C$. armata is similar to $\alpha$-kainic acid in its chemical and biological properties and is called domoic acid (Higa \& Kuniyoshi 2000). The red seaweed Osmundea ramosissima is closely related to D. simplex and C. armata, and although O. ramosissima has not been proven to possess anti-parasitic properties, crude extract from this species is bioactive and can provide a defence against settlement of barnacles (Nylund \& Pavia 2003). The green seaweed Ulva lactuca, on the other hand, is generally considered to lack secondary metabolites and is a preferred food for a large number of marine herbivores (Rogers et al. 1995, Granado \& Caballero 2001). Therefore, this species was used as control food in the present study.

Our aim was to investigate whether the feeding behaviour of the marine herbivorous gastropod species Littorina littorea is correlated with the abundance of parasite infections, and whether the algal diet can prevent parasite infection. In addition, we studied whether the prevalence and abundance of trematode infections in $L$. littorea vary among snail populations at sites with and without large macrophytes. This was tested through observational field studies where the prevalence and abundance of trematode infections were compared between different sites, and through field and laboratory experiments where the consumption and infection status was determined after presenting snails with different diets (Osmundea ramosissima and Ulva lactuca). We specifically hypothesized (1) that there would be a difference in the prevalence and abundance of trematode infections among snails from different populations, (2) that snails from sites with large macrophytes would be less parasitized than snails from sites without large macrophytes, (3) that there would be a significant negative correlation between the amount of seaweed tissue consumed and the abundance of parasite infection, and (4) that healthy snails transplanted to field sites with high trematode prevalence would be more parasitized when offered $U$. lactuca, than when offered O. ramosissima or a combination of the 2 algal species.

\section{MATERIALS AND METHODS}

Field observations. The study was carried out in the archipelago offshore from the Tjärnö Marine Biological Laboratory (TMBL) on the Swedish west coast. In order to estimate and compare the distribution of parasites in adult Littorina littorea, a total of 120 snails were collected in September 2005 from 6 different islands (20 snails from each site). The islands chosen were Långholmen $\left(58^{\circ} 53^{\prime} \mathrm{N}, 11^{\circ} 07^{\prime} \mathrm{E}\right)$, Lökholmen $\left(58^{\circ} 53^{\prime} \mathrm{N}, 11^{\circ} 07^{\prime} \mathrm{E}\right)$, Saltö (58 $\left.52^{\prime} \mathrm{N}, 11^{\circ} 09^{\prime} \mathrm{E}\right)$, Rundö 
$\left(58^{\circ} 52^{\prime} \mathrm{N}, 11^{\circ} 10^{\prime} \mathrm{E}\right)$, Flatskär $\left(58^{\circ} 51^{\prime} \mathrm{N}, 11^{\circ} 08^{\prime} \mathrm{E}\right)$ and Rossö ( $\left.58^{\circ} 51^{\prime} \mathrm{N}, 11^{\circ} 11^{\prime} \mathrm{E}\right)$. The field sites were characterised by sheltered (Långholmen and Lökholmen) and semi-exposed (Flatskär) rocky reef and boulder shores with abundant large macroalgae, or sheltered sandy/ muddy habitats (Saltö, Rundö, and Rossö) with very few, scattered large macrophytes (fucoids), but with benthic microalgae (e.g. diatoms). The snails were immediately brought to the laboratory and killed by freezing to $-70^{\circ} \mathrm{C}$. After thawing, the foot and digestive gland of each individual was squeezed between 2 glass plates. Infections by rediae, sporocysts and metacercariae were observed under a stereomicroscope, and the prevalence of sporocysts/rediae (first intermediate hosts) and metacercariae (second intermediate hosts), as well as the abundances of metacercariae, were recorded. We did not identify the trematodes to species, as this study was aimed at investigating the overall effect of snail diet on trematodes that infect L. littorea. However, Renicola roscovita, Cryptocotyle lingua, and Himasthla elongata are the most common trematodes infecting $L$. littorea in the study area (Granovitch \& Johannesson 2000). No statistical analysis was performed with the data on parasite prevalence, since there was only one sample per site. The data on the abundance of secondary infections were statistically analysed using a nested analysis of variance (ANOVA) with habitat (with or without seaweeds) as a fixed 2-level factor and site as a random 3-level factor nested within habitat.

Consumption experiment 1 - Osmundea ramosissima versus Ulva lactuca. In order to test whether the food consumption of Littorina littorea was correlated with the abundance of trematode infections, a consumption experiment with 2 algal species (Osmundea ramosissima and Ulva lactuca) was carried out in the laboratory in October 2005. A large number (>200) of L. littorina individuals was collected from the field sites identified in the previous observational study, in order to include snails with a range of parasite abundances. The snails were pooled and 40 were chosen haphazardly and placed individually in 0.21 aquaria containing either $O$. ramosissima or $U$. lactuca $(\mathrm{n}=20)$. Control aquaria without snails were also prepared in order to measure the autogenic wet weight changes in the seaweeds during the experiment. The aquaria were connected to a flow-through system with filtered seawater at a temperature of 18 to $20^{\circ} \mathrm{C}$. The experiment was terminated after $48 \mathrm{~h}$, and all snails were removed, dissected, and infection abundances determined. The wet weights of the seaweeds were determined at the start and the end of the experiment, and the wet weight change ( $\%$ of initial wet weight) was calculated. Because growth of the control seaweeds was negligible during the experiment (data not shown), consumption (g wet weight) was calculated by subtracting the final weights from the starting weights of the grazed seaweeds. Consumption by healthy and infected snails was statistically compared by linear regression analyses, with consumption of the algae as dependent variable and abundance of metacercariae as the independent variable.

Field transplant experiment. The field transplant experiment was carried out over $6 \mathrm{wk}$ from October to November 2005 in order to test whether algal diet can prevent parasite infection in Littorina littorea. We collected $360 \mathrm{~L}$. littorea individuals from the island of Flatskär, where infection by digeneans was low (Fig. 1). The snails were kept in the laboratory overnight in running seawater and were not fed during this time. The following day, the snails were placed in cages $\left(10 \mathrm{~cm}^{3}\right)$ with a $1 \mathrm{~cm}$ mesh size, 10 snails in each cage. The cages contained Osmundea ramosissima, Ulva lactuca or a combination of both. The treatment with both seaweed species present was included to increase the ecological relevance of the experiment by allowing the snails to mix diets. Diet mixing may be important if diets rich in secondary metabolites are nutritionally inferior (cf. Singer \& Bernays 2003). Each cage provided more than enough food for each snail, so that the snails would not experience shortages. The

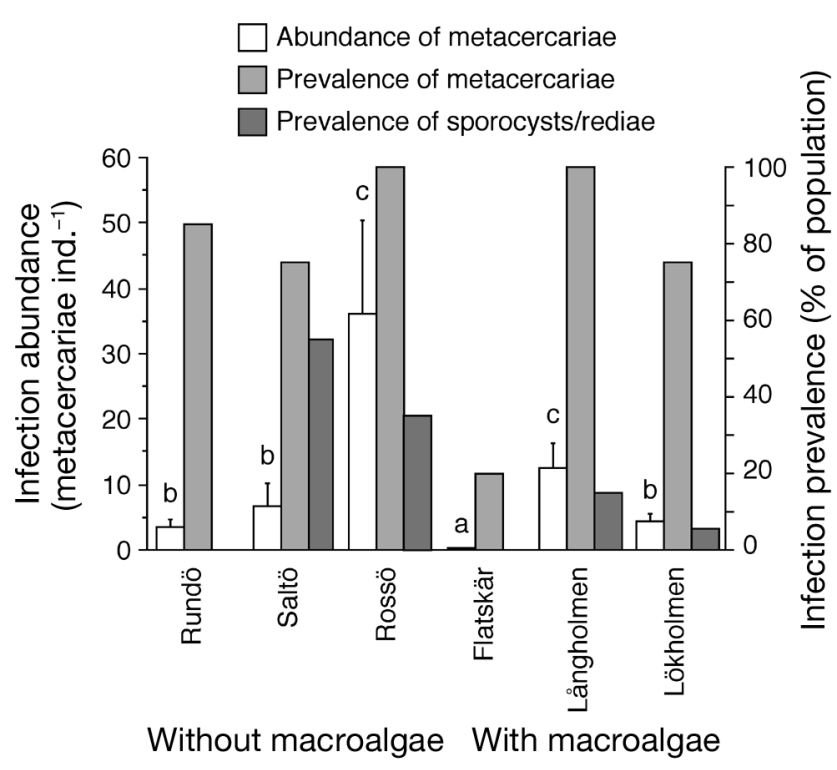

Fig. 1. Littorina littorea. Infection abundance (metacercariae ind $^{-1}$ ), prevalence of metacercariae (\% of population), and prevalence of sporocysts/rediae (\% of population) in snail populations collected in September 2005 from 6 different sites with or without large macrophytes, offshore from the Tjärnö Marine Biological Laboratory on the Swedish west coast. Letters above white bars: significant differences between mean values based on Student-Newman-Keul's multiple-comparisons test $(\mathrm{p}<0.05)$. Data are mean (+ SE for abundance); $\mathrm{n}=20$ 
cages were attached to aluminium frames, 18 cages on each of 2 frames. The frames were kept outside the laboratory in a large container with flow-through seawater for $1 \mathrm{wk}$ prior to transplantation to the islands of Saltö and Rossö. These sites were found to have a high prevalence of first intermediate hosts (field observation, Fig. 1). Cages were inspected weekly and supplied with fresh algae. At the end of the experiment, the snails were brought back to the laboratory, killed and dissected to measure infection status, as described for the field observation, except that only secondary infections were measured. The effect of the 3 treatments (O. ramosissima, U. lactuca, O. ramosissima + $U$. lactuca) on the infection abundance was statistically analysed using a mixed model ANOVA with treatment (3 levels) as fixed, and site (2 levels) as random orthogonal factors, and cage as a random factor nested within the interaction between treatment and site. Data on the infection prevalence in the cages were statistically analysed by a 2-way ANOVA with treatment as a fixed 3-level factor and site as a random 2-level factor.

Consumption experiment 2-Fresh Osmundea ramosissima versus artificial food. Because no significant effect of diets on infection prevalence or abundance was found in the field transplant experiment (see Results), we performed an additional experiment to test the hypothesis that the negative relationship between Littorina littorea consumption and infection abundance found in the initial consumption experiment was due to the morphology, and not the chemistry of $O$. ramosissima. Forty snails were collected from haphazardly chosen sites outside the TMBL and placed individually in $0.2 \mathrm{l}$ aquaria containing either fresh $O$. ramosissima or freeze-dried, homogenized O. ramosissima incorporated into agar-based artificial diets $(1.5 \%$ agar and $10 \%$ O. ramosissima on a dry weight: wet weight basis, $\mathrm{n}=20$ ). Control aquaria without snails were not prepared, because autogenic wet weight changes in seaweeds and artificial diets during the experiment were assumed to be negligible. The aquaria were connected to a flow-through system with filtered seawater at a temperature of 18 to $20^{\circ} \mathrm{C}$. The experiment was terminated after $48 \mathrm{~h}$ when all snails were removed, dissected, and infection abundance determined. The wet weight of the seaweeds and artificial diets was determined at the start and at the end of the experiment, and the consumption ( $g$ wet weight) was calculated by subtracting the final weight from the starting weight. Data were statistically compared by linear regression analyses, with consumption of the algae as the dependent variable and abundance of metacercariae as the independent variable.

Prior to all statistical analyses, data were tested for homogeneity of variances using Cochran's test. All variances were heterogeneous, but only the data on the spatial distribution of trematodes from the field observation were transformed to $\log (x+0.1)$ because transformations of data from the other experiments changed the ranking of mean values (i.e. transformations were not monotonic, cf. Underwood 1997). However, since data were balanced and experiments were performed with a relatively large number of replicates, statistical analyses were performed on untransformed data (cf. Underwood 1997). Significant differences between mean values were statistically analysed using the Student-Newman-Keul's (SNK) multiple-comparison test.

\section{RESULTS}

The abundance of trematode infections in Littorina littorea varied significantly among different sites (ANOVA, $F_{4,114}=22.99, \mathrm{p}<0.001$ ), but there was no statistically significant difference between habitats with or without seaweeds (ANOVA, $F_{1,4}=0.69, \mathrm{p}=$ 0.453). Snail populations from the islands of Rossö and Långholmen had the highest infection abundance, followed by snails from populations on Saltö, Rundö, and Lökholmen (Fig. 1). The least infected snails were found on Flatskär (Fig. 1). The pattern of infection prevalence of secondary intermediate hosts reflected that of the infection abundance, with the population on Flatskär having the lowest prevalence, and Rossö and Långholmen the highest (Fig. 1). The prevalence of first intermediate hosts was generally lower than the prevalence of second intermediate hosts (Fig. 1), with Saltö and Rossö having the highest prevalence followed by Långholmen and Lökholmen, and Rundö and Flatskär entirely lacking first intermediate hosts.

Trematode-infected Littorina littorea consumed less Osmundea ramosissima than healthy snails, as shown by the statistically significant negative relationship between infection abundance and consumption when $L$. littorea was offered $O$. ramosissima in the first consumption experiment (linear regression, $R^{2}=0.220, p=$ 0.037, Fig. 2A). However, no statistically significant relationship between infection abundance and consumption was found when the L. littorea was offered the green seaweed Ulva lactuca (linear regression, $\mathrm{R}^{2}=$ 0.017, p = 0.586, Fig. 2B)

There was no statistically significant difference in infection prevalence between Littorina littorea individuals transplanted to the 2 different field sites and offered different seaweed foods (Table 1, Fig. 3A). Furthermore, there was no statistically significant difference in infection abundance between snails kept in different cages in the transplant experiment (ANOVA, $F_{30,325}=0.93, \mathrm{p}=0.575$ ), and therefore the mean square for the factor cage was pooled with the residual 


\section{A Osmundea ramosissima}

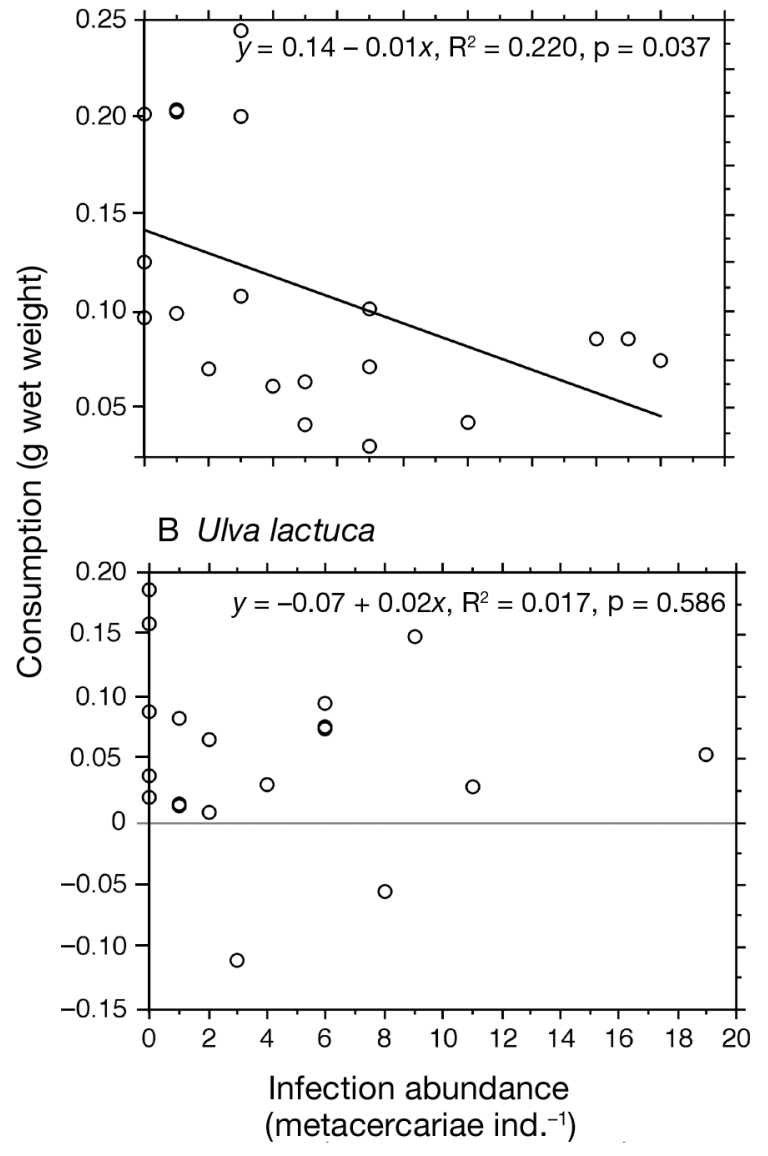

Fig. 2. Littorina littorea. Consumption experiment 1. Consumption vs. infection abundance (metacercariae ind. ${ }^{-1}$ ) in Littorina littorea offered (A) Osmundea ramosissima or (B) Ulva lactuca in the laboratory. $(\mathrm{n}=20)$
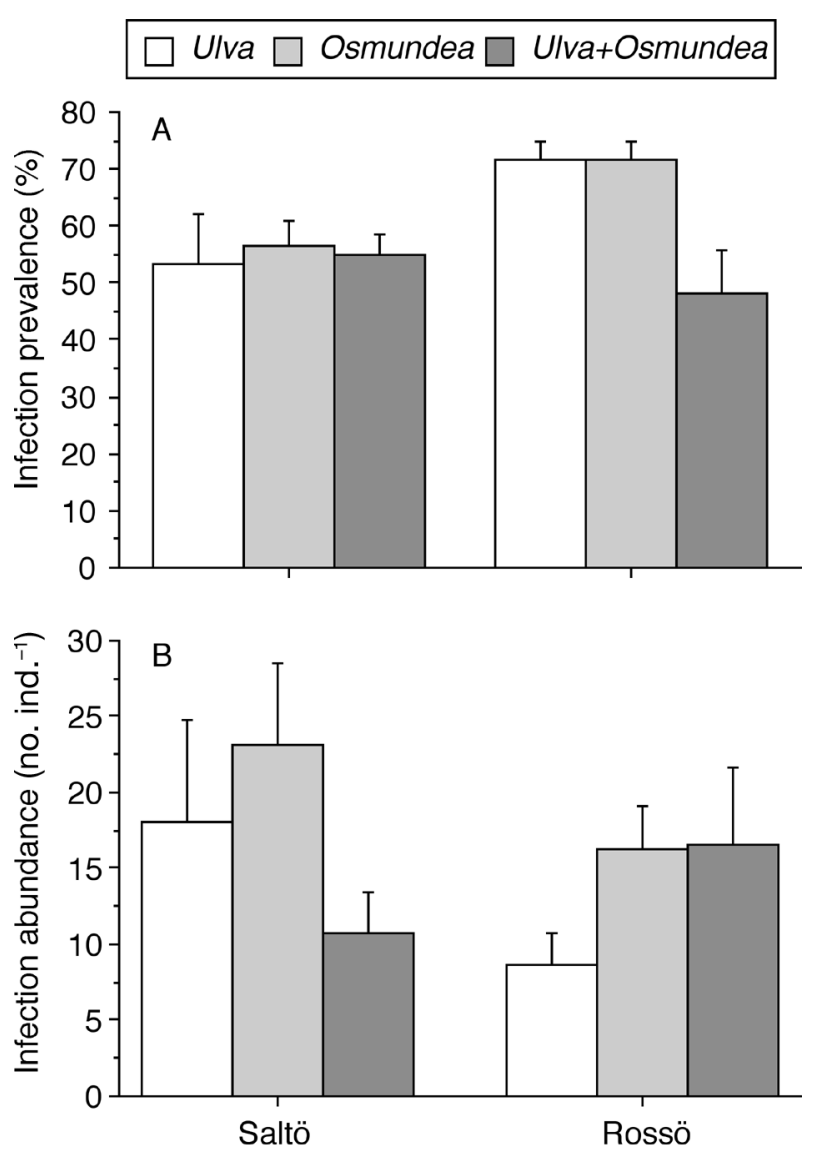

Fig. 3. Littorina littorea. Field transplant experiment. Infection (A) prevalence (\%) and (B) abundance (ind.$^{-1}$ ) of metacercariae in snails transplanted to different sites (Saltö and Rossö) and offered different seaweed diets (Ulva lactuca, Osmundea ramosissima, or a combination of both) for $6 \mathrm{wk}$. Data are mean $+\mathrm{SE} ; \mathrm{n}=6$ in $(\mathrm{A})$ and $\mathrm{n}=60$ in $(\mathrm{B})$
Table 1. Littorina littorea. ANOVA for (A) infection prevalence (\%), and (B) infection abundance (metacercariae ind.$^{-1}$ ) of snails transplanted in cages to different sites (Site) and offered different seaweed food treatments (Treatment). There was no statistically significant difference in infection abundance between snails kept in different cages $(p=0.575)$ and therefore the mean square for the factor cage was pooled with the residual mean square and is not presented in the table. Mean values (+ SE) are in Fig. 3

\begin{tabular}{|c|c|c|c|c|c|}
\hline Source of variance & $\mathrm{df}$ & MS & $F$ & $\mathrm{p}$ & $F$ vs. \\
\hline \multicolumn{6}{|l|}{ Infection prevalence } \\
\hline Treatment & 2 & 553 & 1.000 & 0.500 & Treatment $\times$ Site \\
\hline Site & 1 & 711 & 3.902 & 0.058 & Residual \\
\hline Treatment $\times$ Site & 2 & 553 & 3.034 & 0.063 & Residual \\
\hline Residual & 30 & 182 & & & \\
\hline \multicolumn{6}{|l|}{ Infection abundance } \\
\hline Treatment & 2 & 1544 & 0.777 & 0.563 & Treatment $\times$ Site \\
\hline Site & 1 & 1155 & 0.970 & 0.325 & Residual \\
\hline Treatment $\times$ Site & 2 & 1988 & 1.669 & 0.190 & Residual \\
\hline Residual & 354 & 1190 & & & \\
\hline
\end{tabular}

mean square. Moreover, there was no statistically significant difference in infection abundance between $L$. littorea individuals transplanted to different sites and offered different food treatments (Table 1, Fig. 3B).

In accord with the first consumption experiment, trematode-infected Littorina littorea consumed less fresh Osmundea ramosissima than healthy snails, as shown by the statistically significant negative relationship between infection abundance and consumption when $L$. littorea was offered O. ramosissima in the second consumption experiment (linear regression, $\mathrm{R}^{2}=$ 0.259, $\mathrm{p}=0.022$, Fig. 4A). However, when $O$. ramosissima was dried and incorporated into agar diets, no statisti- 


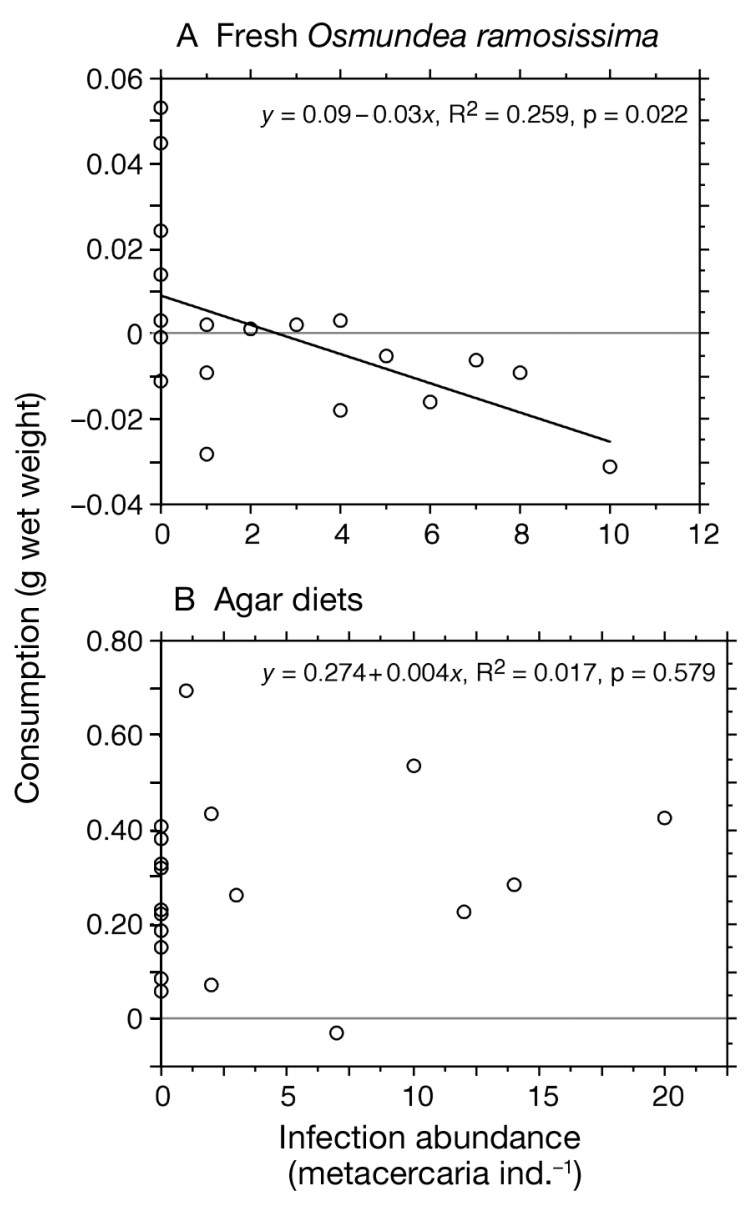

Fig. 4. Littorina littorea. Consumption experiment 2. Consumption vs. infection abundance (metacercariae ind. ${ }^{-1}$ ) in snails offered (A) fresh Osmundea ramosissima or (B) dried, homogenized $O$. ramosissima incorporated into agar-based artificial diets in the laboratory. $(n=20)$

cally significant relationship between $L$. littorea infection abundance and consumption was found (linear regression, $\mathrm{R}^{2}=0.017, \mathrm{p}=0.579$, Fig. 4B), indicating that the significant relationship between consumption of fresh O. ramosissima and infection status of $L$. littorea was due to algal morphology rather than algal chemistry.

\section{DISCUSSION}

The results from the consumption experiment showed that Littorina littorea with low number of metacercariae fed on Osmundea ramosissima to a greater extent than snails with high infection intensity. However, there was no significant correlation between infection intensity and consumption when L. littorea were offered the green seaweed Ulva lactuca. These results indicate that the decreased consumption of $O$. ramosissima by infected $L$. littorea was not due to parasite induction of anorectic behaviour in the snails (cf. Hart 1990), as this would have also negatively affected the consumption of $U$. lactuca by infected snails. The capability of parasites for altering the behaviour of their hosts is now well accepted, and in most cases the altered behaviour is hypothesised to benefit the parasites (e.g. Karban \& English-Loeb 1997, Levri 1999, McCarthy et al. 2000). Therefore, were $O$. ramosissima to contain metabolites that reduce parasite fitness, the negative relationship between infection abundance and consumption of $O$. ramosissima by infected $L$. littorea could have been caused by manipulation of snails' feeding behaviour by the parasites. However, the field experiment (where healthy snails were offered different algal food while simultaneously exposed to free-living cercariae) did not show that $O$. ramosissima prevented trematode infection in L. littorea. The mean metacercarial abundance increased in snails after transplantation from a site with low prevalence of trematodes to a site with high prevalence, but there was no significant difference in parasite resistance between snails offered different algal diets. An alternative explanation for the reduced consumption of $O$. ramosissima by infected L. littorea is that heavily infected snails were weaker than healthy snails and therefore had difficulties grazing the relatively tough $O$. ramosissima. In contrast, $U$. lactuca is a morphologically simple alga with low toughness that both infected and healthy snails are able to graze upon (cf. Rogers et al. 1995). This alternative explanation was supported by the second consumption experiment, where no significant correlation between consumption and infection abundance was found when snails were offered O. ramosissima incorporated into soft agar-based diets. These results indicate that the morphology of $O$. ramosissima, rather than its chemistry, affected the consumption by infected L. littorea.

Although no support was found for the hypothesis that Osmundea ramosissima prevented trematode infection in Littorina littorea, there was a large spatial variation in both the prevalence and abundance of trematode infections between different $L$. littorea populations, in accord with previous investigations in the study area (Granovitch \& Johannesson 2000, Svärdh \& Johannesson 2001, Granovitch \& Mikhailova 2004). A variety of algal foods at different sites might increase the mean nutritional value of the food, which may compensate for the nutritional deficiency to which a parasitized animal is usually subjected, and thereby enhance the immune function (cf. Hutchings et al. 2003). Littorina littorea is a generalist grazer that consumes a large variety of macroalgae, as well as epiphytic and 
benthic microalgae (authors' pers. obs.). The sites included in the present study had either an abundance of different species of red, green and brown macroalgae (including O. ramosissima and U. lactuca), or were almost devoid of macroalgae, though benthic microalgae were present. Therefore, the available diet for L. littorea was most likely more diverse in sites with abundant macrophytes. However, there was no statistically significant difference in the trematode abundances between habitats with or without large macroalgae, indicating that the significant variation between different sites was due to factors other than the presence/absence of large macrophytes.

There are several alternative hypotheses explaining the large spatial variation in trematode abundance observed among Littorina littorea populations in the present study. Although not quantified or statistically tested, both the prevalence and intensity of trematode infections in L. littorea appeared to be correlated to the degree of wave exposure at different sites, in accord with observations in earlier studies (e.g. Curtis 2002, Granovitch \& Johannesson 2000). In both miracidia and cercariae, host searching occurs in 3 distinct steps: (1) finding of host habitat, (2) random search, and (3) chemoattraction to the host (Sukhdeo \& Sukhdeo 2004). Strong wave motion on exposed shores may prevent free-living stages of trematodes from remaining in the host habitat and infecting new individuals (Granovitch \& Johannesson 2000). Furthermore, the intermediate hosts that are involved in the life cycle of trematodes are rare in exposed habitats (Granovitch \& Johannesson 2000). High prevalence of parasites in L. littorea at sheltered shores may also relate to the considerable input of infective propagules from waterfowl (McCarthy et al. 2000, Curtis 2002).

Algal derived compounds are important mediators of marine tri-trophic interactions (i.e. ecological interactions involving 3 trophic levels). For example, marine herbivores (especially opisthobranch molluscs) sequester food-derived secondary metabolites in their tissues and egg masses, and use them as a chemical defences against predators (Stachowicz 2001). Ours is the first test of the hypothesis that the algal diet prevents parasite infection in marine herbivores, albeit that there was no effect of Osmundea ramosissima on total trematode infections in Littorina littorea. However, our results must be regarded as preliminary, because of the limited number of species tested. This hypothesis should be tested using other algal and herbivore species before drawing general conclusions on the effect of diet on parasitism in marine organisms.

Acknowledgements. We are grateful to all staff and students at Tjärnö Marine Biological Laboratory for their helpfulness and encouragement. H. Pavia and 3 anonymous reviewers provided valuable comments on earlier versions of the manu- script. This study was financially supported by MARICE (Marine Chemical Ecology, an interdisciplinary research platform at the Faculty of Sciences, Göteborg University, Sweden), and by the Swedish Research Council through contract no. 621-2003-2883 to G.B.T.

\section{LITERATURE CITED}

Curtis LA (2002) Ecology of larval trematodes in three marine gastropods. Parasitol 124:43-56

Desclaux C, de Montaudouin X, Bachelet G (2004) Cockle Cerastoderma edule population mortality: role of the digenean parasite Himasthla quissetensis. Mar Ecol Prog Ser 279:141-150

Esch GW, Curtis LA, Barger MA (2001) A perspective on the ecology of trematode communities in snails. Parasitol 123:S57-S75

Galaktionov KV, Bustnes JO (1999) Distribution patterns of marine bird digenean larvae in periwinkles along the southern coast of the Barents Sea. Dis Aquat Org 37: 221-230

Granado I, Caballero P (2001) Feeding rates of Littorina striata and Osilinus atratus in relation to nutritional quality and chemical defences of seaweeds. Mar Biol 138: 1213-1224

Granovitch A, Johannesson K (2000) Digenetic trematodes in four species of Littorina from the west coast of Sweden. Ophelia 53:55-65

Granovitch A, Mikhailova NA (2004) Rocky shore trematodes of the west coast of Sweden: distribution and life cycle strategies. Acta Parasitol 49:228-236

Hart BL (1990) Behavioral adaptations to pathogens and parasites: five strategies. Neurosci Biobehav Rev 14:273-294

Higa T, Kuniyoshi M (2000) Toxins associated with medicinal and edible seaweeds. J Toxicol Toxin Rev 19:119-137

Hudson PJ, Dobson AP, Newborn D (1998) Prevention of population cycles by parasite removal. Science 282: 2256-2258

Huffman MA (2003) Animal self-medication and ethnomedicine: exploration and exploitation of the medicinal properties of plants. Proc Nutr Soc 62:371-381

Hutchings MR, Athanasiadou S, Kyriazakis I, Gordon IJ (2003) Can animals use foraging behaviour to combat parasites? Proc Nutr Soc 62:361-370

Huxham M, Raffaelli D, Pike A (1993) The influence of Cryptocotyle lingua (Digenea:Platyhelminthes) infections on the survival and fecundity of Littorina littorea (Gastropoda:Prosobranchia); an ecological approach. J Exp Mar Biol Ecol 168:223-238

Karban R, English-Loeb G (1997) Tachinid parasitoids affect host plant choice by caterpillars to increase caterpillar survival. Ecology 78:603-611

Levri EP (1999) Parasite-induced change in host behavior of a freshwater snail: parasitic manipulation or by product of infection? Behav Ecol 10:234-241

McCarthy HO, Fitzpatrick S, Irwin SWB (2000) A transmissible trematode affects the direction and rhythm of movement in a marine gastropod. Anim Behav 59:1161-1166

Mouritsen KN, Poulin R (2002) Parasitism, community structure and biodiversity in intertidal ecosystems. Parasitology 124:S101-S117

Nylund GM, Pavia H (2003) Inhibitory effects of red algal extracts on larval settlement of the barnacle Balanus improvisus. Mar Biol 143:875-882

Rogers CN, Steinberg PD, de Nys R (1995) Factors associated with oligophagy in two species of sea hares (Mollusca: 
Anaspidea). J Exp Mar Biol Ecol 192:47-73

Rohde K (2005) Marine Parasitology. CABI Publishing, Wallingford

Sato M, Naakano T, Taeuchi M, Kanno N, Nagahisa E, Sato Y (1996) Distribution of neuroexcitatory amino acids in marine algae. Phytochem 42:1595-1597

Scott ME (1988) The impact of infection and disease on animal populations: implications for conservation biology. Conserv Biol 2:40-56

Singer MS, Bernays EA (2003) Understanding omnivory needs a behavioural perspective. Ecology 84:2532-2537

Singer MS, Stireman JO (2003) Does anti-parasitoid defence explain host-plant selection by polyphagous caterpillar? Oikos 100:554-562

Singer MS, Carrière Y, Theuring C, Hartmann T (2004) Disentangling food quality from resistance against parasitoids: diet choice by a generalist caterpillar. Am Nat 164 : 423-429

Skirnisson K, Galaktionov KV, Kozminsky EV (2004) Factors

Editorial responsibility: Antony Underwood (Contributing

Editor), Sydney, New South Wales, Australia influencing the distribution of digenetic trematode infections in a mudsnail (Hydrobia ventrosa) population inhabiting salt marsh ponds in Iceland. J Parasit 90:50-59

Smit AJ (2004) Medicinal and pharmaceutical uses of seaweed natural products: a review. J Appl Phycol 16:245-262

Stachowicz JJ (2001) Chemical ecology of mobile benthic invertebrates: predator and prey, allies and competitors. In: McClintock JB, Baker BJ (eds) Marine chemical ecology. CRC Press, Boca Raton, FL, p 157-194

Sukhdeo MVK, Sukhdeo SC (2004) Trematode behaviours and the perceptual worlds of parasites. Can J Zool 82: $292-315$

Svärdh L, Johannesson K (2001) Incidence of hematocytes and parasites in coastal populations of blue mussels (Mytilus edulis) - testing correlations with area, season, and distance to industrial plants. J Inv Path 80:22-28

Underwood AJ (1997) Experiments in ecology: their logical design and interpretation using analysis of variance. Cambridge University Press, Cambridge

Submitted: October 3, 2006; Accepted: May 8, 2007

Proofs received from author(s): October 4, 2007 